\title{
An Archaeointensity Investigation of a Kiln at Pompeii
}

\author{
M. E. EvanS \\ Institute of Earth \& Planetary Physics, University of Alberta, Edmonton, Alberta, Canada T6G 2J1 \\ (Received August 1989; Revised November 1990)
}

\begin{abstract}
Archaeomagnetic measurements on a kiln thought to be operating at the time of the Pompeii disaster, 24th August 79 A.D., indicates a normal field direction with an archaeointensity value of 61 microtesla. The low error and precise date makes this an important reference point to which other less accurately dated results can be compared.
\end{abstract}

\section{Introduction}

One of the most persistent difficulties encountered in archaeomagnetic work is the paucity of firm dates to which experimental results can be tied. It was therefore a happy occasion-and a great privilege-when the opportunity arose to sample a kiln at Pompeii. The kiln in question is located in an oil-lamp workshop (officina di lucerne) near the Noceria Gate (region I, 20). It is of brick construction $(1.5 \mathrm{~m} \times 1.5 \mathrm{~m}$ ) and is in an excellent state of preservation. When it was excavated it was found to be full of lamps, suggesting that it was operational at the time of the Vesuvian eruption which destroyed the town. Thus its last firing was probably within weeks of the disaster of 24th August 79 A.D.

Nine oriented samples were collected. One of them is an irregular piece of a broken brick (max. dimension $14 \mathrm{~cm}$ ), the other eight samples are $25 \mathrm{~mm}$ diameter cores obtained with a portable gasoline-driven drill. Orientation was by means of solar bearings. All the samples are from the walls of the firing chamber at heights of less than $50 \mathrm{~cm}$ above the perforated floor.

\section{Archaeodirections}

The samples carry a remanence that is strong enough to be easily and accurately measured, but not so strong that significant distortion by internal demagnetization is to be expected (intensities fall in the range 1-2 $\mathrm{Am}^{-1}$ ). The NRM directions form a tight group centred on $D=358.0^{\circ}, I=59.1^{\circ}\left(k=952, \alpha_{95}=1.7^{\circ}\right)$ as reported elsewhere by EVANS and MARESCHAL (1989). During incremental alternating field (AF) demagnetization up to $100 \mathrm{mT}$ there is very little movement, and the mean never strays more than $1^{\circ}$ from the NRM mean. The precision parameter $(k)$ decreases slightly at first but then stabilizes around a value of about 500 (the lowest value actually occurs at $40 \mathrm{mT} ; k=484$, $\alpha_{95}=2.3^{\circ}$.

\section{Archaeointensities}

To complement the directional study an archeointensity investigation has now been 
undertaken. The procedure used is essentially that described by SHAW (1974) with minor modifications (EVANS, 1986). Six specimens were studied, and the results are relatively straightforward. The main problem of interpretation arises from the trade-off between seeking the best linear relationship between NRM and laboratory-induced TRM (as measured by regression line correlation coefficients) and the desire to retain as much of the coercive force spectrum as possible. Since there is no generally accepted procedure, the NRM-TRM plots are presented for the reader's own assessment (Fig. 1). These plots refer to the coercive force range 2.5 to $40 \mathrm{mT}$. This window covers the bulk of the magnetizations, but has been selected for two specific reasons. At the lower end the untreated (total NRM, total TRM) points are ignored because of occasional small angular shifts during the first demagnetization step. At the higher end the points beyond $40 \mathrm{mT}$ are excluded because it was found that the anhysteretic remanences (ARM's) (used in this technique to monitor mineralogical change) were very weak at the higher AF treatments and could not be accurately measured. This situation parallels that found in an earlier study (EVANS, 1986).

For three samples $(1,4,5)$ the entire $2.5-40 \mathrm{mT}$ window can be used to obtain

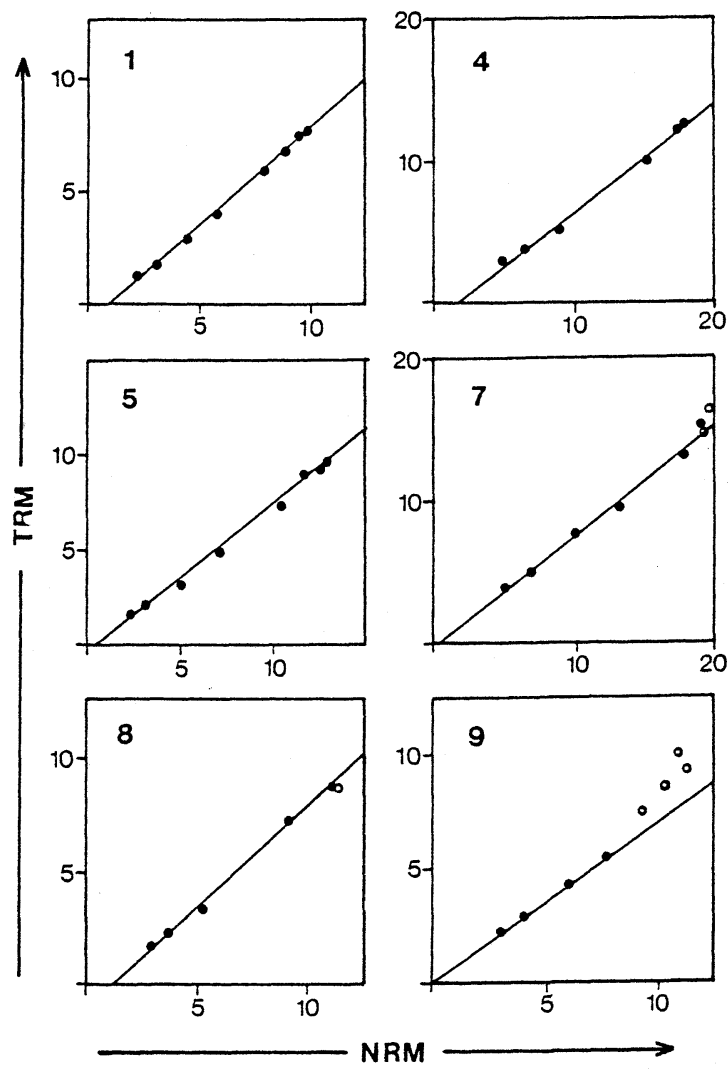

Fig. 1. NRM-TRM plots. Open circles represent omitted points as explained in the text. For samples 1, 5, 7 and $9 \mathrm{AF}$ treatments are 2.5, 5, 7.5, 10,15,20,30 and $40 \mathrm{mT}$, for samples 4 and 8 the 7.5 and $15 \mathrm{mT}$ steps were omitted. Magnetic moments are in units of $\mu \mathrm{Am}^{2}$. 
archaeointensity estimates, but the other three require some comment. For sample 7 the 2.5 and $5 \mathrm{mT}$ points are rejected because of the observed non-monotonic trend due to the $5 \mathrm{mT}$ TRM datum exhibiting a spurious local minimum. For sample 8 the $2.5 \mathrm{mT}$ point is rejected as it lies off the trend defined by the other points. These two modifications are extremely minor and make absolutely no difference to the overall result. The only important decision involves sample 9. This seems to have lost some soft NRM, like many of the samples reported by Shaw in his original paper. I have followed his procedure of rejecting low-coercivity points until a good straight line emerges. The results are summarized in Table 1 from which it can be seen that the linear relationships are very convincing; the worst NRM-TRM correlation coefficient is 0.995 . The ARM curves are not presented graphically but the appropriate regression data are included in Table 1; correlation coefficients equal or exceed 0.995 except for sample 9 which is based on only 4 points and yields a slightly lower value of 0.984 .

The slopes of the regression lines convert to the archaeointensity estimates listed in column 7; these range between 56 and $68 \mu \mathrm{T}$ with a mean and standard error of $62 \pm 2 \mu \mathrm{T}$. However, it is apparent from column 3 that in four of the six cases the ARM's do not qualify these samples as Kono type I (KONO, 1978). In other words, the slopes of the ARM regression lines differ significantly from unity. The range of behaviours runs from sample 8 which has enhanced remanence-carrying capacity after laboratory heating (by $15 \pm 5 \%$ ) to sample 5 which has $11 \pm 3 \%$ less capacity after heating. These are not large changes and I therefore adopt Kono's procedure of correcting the archaeointensity estimates accordingly (column 8 of Table 1 ). Now the range of values is reduced (57 to 64 $\mu \mathrm{T})$ but the mean is not much affected $(61 \pm 1 \mu \mathrm{T})$.

There are both theoretical and experimental grounds for expecting that TRM moments depend on the rate of cooling, and some authors apply a correction factor to allow for the rapidity of laboratory cooling compared to that presumably in effect during the original kiln-firing in antiquity. As AITKEN (1983) points out, it is only for the small samples used with SQUID magnetometers that this effect becomes significant (about $10 \%)$. Nevertheless, in order to check this effect for the cores $(25 \mathrm{~mm}$ diameter, $25 \mathrm{~mm}$ long) used in the present study, two of the samples were reheated and allowed to gain a

Table 1. Summary of palaeointensity estimates.

\begin{tabular}{cccccccc}
\hline 1 & 2 & 3 & 4 & 5 & 6 & 7 & 8 \\
\hline 1 & 8 & $1.070 \pm 0.045$ & 0.995 & $0.863 \pm 0.013$ & 0.999 & 56.8 & 60.7 \\
4 & 6 & $0.955 \pm 0.033$ & 0.998 & $0.763 \pm 0.029$ & 0.997 & 64.2 & 61.4 \\
5 & 8 & $0.886 \pm 0.031$ & 0.996 & $0.778 \pm 0.027$ & 0.996 & 64.3 & 56.9 \\
7 & 6 & $0.998 \pm 0.029$ & 0.998 & $0.793 \pm 0.038$ & 0.995 & 63.1 & 62.9 \\
8 & 5 & $1.145 \pm 0.054$ & 0.997 & $0.882 \pm 0.035$ & 0.998 & 55.6 & 63.6 \\
9 & 4 & $0.902 \pm 0.115$ & 0.984 & $0.718 \pm 0.007$ & 1.000 & 68.3 & 61.6 \\
\hline & & & & Means & $62.1 \pm 2.0$ & $61.2 \pm 1.0$ \\
\hline
\end{tabular}

Notes: The numbered columns contain the following: 1: sample name; 2 : number of data points used for regression; 3 and 4: slope of ARM1-ARM2 regression line and corresponding correlation coefficient; 5 and 6 : slope of NRM-TRM regression line and corresponding correlation coefficient; 7: paleofield intensity in $\mu$ T, before Kono correction; 8: same as 7, after correction. In all cases the statistical uncertainty limits are standard errors. 
TRM over a time interval in excess of 5 hours, compared to about 20 minutes in the first series of experiments. Sample PP04 acquired a slightly stronger (+2\%) TRM after slow cooling, but PP08 was actually weaker $(-0.7 \%)$. It appears that, under the experimental conditions employed here, the cooling rate effect is negligible in these samples; the intensity estimates obtained have not been modified.

\section{Discussion and Conclusions}

A global summary of archaeomagnetic intensity results (MCELHINNY and SENANYAKE, 1982) indicates that the Earth's dipole moment has decreased markedly during the last two millenia, but not at a uniform rate. For the first millenium A.D. the moment had a steady value close to $11 \times 10^{22} \mathrm{Am}^{2}$ after which it decreased rapidly to its present value of about $8 \times 10^{22} \mathrm{Am}^{2}$. This decrease may be due to the appearance of patches of reverse flux at the core-mantle boundary as suggested by GUBBINS (1987).

A geocentric axial dipole of $11 \times 10^{22} \mathrm{Am}^{2}$ produces a field of $64 \mu \mathrm{T}$ at the latitude of Pompeii, close to the experimental estimates reported here. This suggests that the nondipole field in Italy was small during the latter part of the 1 st century A.D. The directional results support this finding since the declination is close to true North (it is actually $2.0^{\circ} \mathrm{West}$ ) and the inclination is less than $1^{\circ}$ shallower than the theoretical value $\left(59.1^{\circ}\right.$ compared to $\left.59.9^{\circ}\right)$. The non-dipole field implied by these data has a magnitude of $3.3 \mu \mathrm{T}$ (directed upwards in the SW quadrant; $D=234^{\circ}, I=-66^{\circ}$ ). The modern field has non-dipole components generally much larger than this. For example, the 1965 IGRF has a non-dipole component less than $3.3 \mu \mathrm{T}$ only in the so-called Pacific Dipole Window (DOELL and COX, 1972) in an area bounded approximately by the 120 and $180^{\circ} \mathrm{W}$ meridians and by the equator and the $70^{\circ} \mathrm{N}$ latitude line, somewhat less than $10 \%$ of the Earth's surface. One view of the Pompeii result is therefore in terms of an ancient "dipole window" of unknown extent and duration.

In a recent discussion however AITKEN et al. (1989) offer a quite different interpretation. They argue that an overview of mid-northerly latitude archaeointensity data covering the last 4000 years suggests that the dominant source of variations was a westward drifting non-dipole feature. A complete discussion of this sharp conflict is beyond the scope of this paper, nevertheless it is to be hoped that reliable, well-dated results of the kind reported here will eventually enable the matter to be settled.

This work was supported by a grant from the Natural Sciences and Engineering Research Council of Canada. I am very grateful to the Soprintendenza Archeologica responsible for Pompeii for permission to sample. I am indebted to Gerry Hoye for writing the computer programs used herein and for many stimulating discussions.

\section{REFERENCES}

AITKEN, M. J., Basic techniques for archaeointensity determination, in Geomagnetism of Baked Clays and Recent Sediments, edited by K. M. Creer, P. Tucholka, and C. E. Barton, pp. 78-87, Elsevier, 1983.

Aitken, M. J., A. L. Allsop, G. D. Bussell, and M. B. Winter, Geomagnetic intensity variation during the last 4000 years, Phys. Earth Planet. Inter., 56, 49-58, 1989.

Doel.t, R. R. and A. Cox, The Pacific geomagnetic secular variation anomaly and the question of lateral uniformity in the lower mantle, in The Nature of the Solid Earth, edited by E. C. Robertson, pp. 245-284, McGraw-Hill, 1972. 
Evans, M. E., Paleointensity estimates from Italian kilns, J. Geomag. Geoelectr., 38, 1259-1267, 1986.

EvAnS, M. E. and M. MARESCHAL, Secular variation and magnetic dating of fired structures in southern Italy, in Archaeometry, Proc. 25th Int. Symp., edited by Y. Maniatis, pp. 59-68, Elsevier, 1989.

GubBins, D., Mechanism for geomagnetic reversals, Nature, 326, 167-169, 1987.

KonO, M., Reliability of paleointensity methods using alternating field demagnetization and anhysteretic remanence, Geophys. J. R. Astron. Soc., 54, 241-261, 1978.

MCElhinny, M. W. and W. E. SenAnYAKe, Variations in the geomagnetic dipole 1: The past 50,000 years, $J$. Geomag. Geoelectr., 34, 39-51, 1982.

Shaw, J., A new method of determining the magnitude of the paleomagnetic field, Geophys. J. R. Astron. Soc., 39, 133-141, 1974. 